\title{
11-12 Yaş Çocuklarda Somatotip Özelliklere Bağlı Dinamik Dengelerinin
}

\author{
Karşılaşturılması
}

\section{Comparison of Dynamic Balance Based on Somatotype Properties in 11-12 Years Old Children}

\author{
ORİJINAL ARAŞTIRMA/ \\ ORIGINAL RESEARCH \\ Abdurrahman DEMIR ${ }^{1 \dagger}$ \\ Manolya AKIN²
}

${ }^{1}$ Çoruh Üniversitesi, Beden Eğitimi ve Spor Yüksekokulu, Artvin https://orcid.org/0000-0002-3944-4085

${ }^{2}$ Mersin Üniversitesi, Beden Eğitimi ve Spor Yüksekokulu, Mersin https://orcid.org/0000-0002-2101-073X

\begin{abstract}
$\ddot{\mathbf{O z}}$
Bu çalışmanın amacı çocuklarda somatotip özelliklerin belirlenmesi ve somatotip özelliklere bağlı, çocukların dinamik denge becerilerinin karşılaştırılmasıdır. Ayrıca belirlenen somatotip özelliklerinin sportif branș seçimlerinde ne derece yardımcı olduğunun incelenmesi amaçlanmıştır. Araştırmaya normal motor becerileri olan 123 sağlıklı sedanter erkek çocuk $(11,66 \pm, 699$ y1l, 143,93 $\pm 7,14 \mathrm{~cm} .39,54 \pm 9,96 \mathrm{~kg})$ katılmıştır. Araştırmaya katılım Helsinki deklarasyonunun (1964) gerektirdiği şekilde bilgilendirilmiş onam formları ile velilerden izin alınarak, gönüllülük esasına dayalı yapılmıştır. Araştırmada betimsel tarama modeli kullanılmıştır. Somatotip özellikler 'Heath-Carter Antropometrik Somatotipi Hesaplanma' tekniği ile hesaplanmıştır. Dinamik denge ölçümleri Tecno Body ölçüm cihazı ile çift, sağ ve sol ayak kullanılarak katedilen mesafe (PL) değerleri ile ölçülmüştür. Araştırmaya katılan sedanter çocukların somatotip ortalamaları endomorfi $=4,17$, mezomorfi $=4,38$, ektomorfi $=2,62$ olarak bulunmuştur. Baskın endomorf, mezomorf ve ektormorf öğrenciler gruplara ayrılmış ve dinamik denge karşılaştırmaları 'tek yönlü anova' ile yapılmıştır. Dinamik denge özelliğinde, baskın mezomorf olan grup lehine istatiksel olarak anlamlı fark olduğu bulunurken $(\mathrm{p}<, 05)$ baskın endomorf ve ektomorf gruplar arasında anlamlı fark olmadığı bulunmuştur $(\mathrm{p}>, 05)$. Sonuç olarak kaslı yapıda mezamorf özellikleri baskın olan çocukların motorsal becerilerde de daha iyi olabileceği algısına varılmıştır. Okul çağı sedanter çocukların, somatotip özelliklerinin ortaya konmasının ve dinamik dengelerinin incelenmesinin literatüre katkı sağlayacağı düşünülmektedir.
\end{abstract}

Anahtar Kelimeler: Okul Çocukları, Somatotip, Dinamik Denge

\begin{abstract}
The aim of this study was to determine the somatotype properties and to compare the dynamic balance ability of somatotype properties. In addition, determined somatotype properties were intended to help in the selection of sports branches. 123 healthy sedentary boys $(11,66 \pm, 699$ years, $143,3 \pm 7.14 \mathrm{~cm}, 39,54 \pm 9,96 \mathrm{~kg})$ with normal motor skills were enrolled in this study. Participation in the study was based on volunteerism with the consent of the parents with informed consent forms as required by the Helsinki Declaration (1964). Descriptive survey model was used in the research. Heath-Carter Anthropometric Somatotype calculation technique was used to find somatotype properties. Dynamic balance was measured with the Tecno Body instrument using the distance (PL) values which were used by double, right and left feet. The somatotype averages of sedentary children were found to be endomorphic $=4,17$, mesomorphic $=4,38$, ectomorphic $=2,62$. The dominant endomorph, mesomorph and ectormorph students were divided into groups and dynamic equilibrium comparisons were made with one-way Anova. A statistically significant difference was found in favor of the dominant mesomorph group in dynamic balance $(\mathrm{p}<, 05)$, but it was found that there was no significant difference between dominant endomorph and ectomorph groups ( $p>, 05)$. In conclusion, it was concluded that children with dominant musculoskeletal mesomorph characteristics might be better at motor skills. It is thought that examining the somatotype characteristics and dynamic balances of school age sedentary children will contribute to the literature.
\end{abstract}

Keywords: School Children, Somatotype, Dynamic Balance

\footnotetext{
† Sorumlu yazar: Abdurrahman DEMİ, ademir@artvin.edu.tr
} 


\section{GíRiş}

Çocuklarda somatotip ölçümlerin yapılması ve çocukların somatotip özeliklerine göre, spora yönlendirilmelerinin önemli olduğu bildirilmiştir (Lidor, Falk, Arnon ve Cohen, 2005). Boy, vücut ağırlığı ve diğer fiziksel özellikler, çocukların hangi branşı seçmeleri konusunda çok önemli bir etken olabileceği için, fiziksel özelikler ile spor performansı arasındaki ilişki araştırma konusu olmuştur (Akça ve Müniroğlu, 2006; Sögüt, Müniroğlu ve Deliceoğlu, 2004). Somatotip, vücut şeklini kategorize ederek, fiziksel sınıflandırma sistemi, insanların mevcut morfolojik yapılarının belirlenmesi ve sayısal olarak ifade edilmesi olarak tanımlanmaktadır (Sánchez-Muñoz, Sanz ve Zabala, 2007). Somatotip, endomorfi (vücudun yağ oranının fazlalığı), mezomorfi (iskelet kas yapısının gelişmişliği ve güçlülüğ̈̈), ve ektomorfi (iskelet kas yapısının zayıflığı ve inceliği) olmak üzere üç ana kategoriye ayrılmıştır (Carter, 1990). Spor yapan çocukların somatotip özellikleri ya da vücut ölçümleriyle ilgili araştırmalar mevcuttur (Buśko, Pastuszak ve Kalka, 2017; Eler, 2018; Kabakcı ve Yücel, 2016). Bu araştırmalar sportif performans ve fizyoloji arasındaki ilişkiyi araştırıp sporcular arasında karşılaştırma yapmıştır. Ancak sedanter çocuklar üzerinde yapılan araştırmalar sınırlı sayıdadır. Her spor branşının kendine özgü somatotip yapısı bulunmaktadır. İdeal somatotip ve vücudun ideal kompozisyonu herhangi bir spor branşının önemli bir fonksiyonudur (Kürkçü, Hazar ve Özdağ, 2009). Seçilen branşa uygun bir fiziksel yap1 yoksa sporda istenilen başarıyı elde etmenin pek mümkün olmayacağ söylenmektedir (Eyyüpoğlu, Köklü, Özkan ve Akın, 2010) Ayrıca somatotipin hem çocuklarda hem de yetişkinlerde yüksek performans açısından oldukça önemli olduğu ve çocukların hangi branşa yöneleceği konusunda yardımcı olduğu vurgulanmıştır (Geladas, Nassis ve Pavlicevic, 2005; Marta ve ark., 2013).

Denge, birçok kasın birlikte çalışması ile duyusal bilginin düzenlenmesini gerektirir. Özellikle alt ekstremite motor aktivitelerin tümü, vücudun yer çekimine karşı ağırlık merkezini kurabilmesi içindir. Ayakta stabil bir şekilde durulduğunda, bu pozisyonu devam ettirebilmek için propriyosepsiyon duyusunun önemli rolü vardır. Farklı pozisyonlarda dururken ise vizüel ve vestibüler sistemler dengeyi kurmaya yardımcı olurlar (Beğen, 2008). Dinamik denge, ağırlık merkezinin sürekli değiştiği denge türüdür. Yürüme, ağırlık aktaran hareketler, merdiven inme ve çıkma, oturma, kalkma gibi günlük basit eylemlere ait çeşitli hareket örüntüleri ile bu örüntüler arasındaki uyumu içerir. Birey hareket halinde iken denge kontrolü dinamiktir (Chaudhari ve Andriacchi, 2006). 
Demir, A., ve Akın, M. (2019). 11-12 yaş çocuklarda somatotip özelliklere bağlı dinamik dengelerinin karşılaştırılması. CBÜ Beden Eğitimi ve Spor Bilimleri Dergisi, 14(1), 139-150.

Yağ dokusunun fazla olmasının gençler arasında dengeyi bozduğu bildirilmiştir (Salimi, Heidari ve Salimi, 2016). Fazla kilonun ve fiziksel aktivitedeki azalmanın düşük denge kabiliyetine neden olduğu vurgulanmaktadır (Tookuni ve ark., 2005). Ayrıca dinamik denge ile boy ve kilo arasında önemli bir negatif ilişkinin olduğu sonucu da bildirilmektedir (Davlin, 2004). Somatotip özelliklerin, sportif performansı etkilediği ve elit sporcular için iyi bir denge özelliğinin olması gerektiği belirtilmiştir (Top ve ark., 2018). Bu bilgiler ışığında, sedanter çocuklarda somatotip özelliklerin belirlenmesi ve denge testlerinin yapılması ile önemli veriler elde edilebilir. Tüm spor branşları ele alındığında tek bir somatotip karakterin diğerlerine göre avantajlı olduğunu söylemek doğru olmayabilir. Böylece düzenli spor yapmayan sedanter çocukların somatotip karakterlerini belirlemenin ve dinamik dengelerini ölçmenin, objektif sonuçlar ortaya çıkarabileceği düşünülmektedir. Bundan dolayı bu araştırmanın amacı okul çağı çocuklarının spora başlamadan önce branşa uygun somatotip özelliklere sahip olup olmadığının belirlemek ve dinamik denge değerleri arasındaki farkı değerlendirmektir.

\section{YÖNTEM}

\section{Katılımelar}

$\mathrm{Bu}$ araştırmaya yaşları, boyları ve vücut ağırlıkları sırasıyla 11,66, \pm 699 yıl, 143,93 $\pm 7,14$ cm. 39,54 $\pm 9,96$ kg. olan 123 sağlıklı sedanter erkek çocuk katılmıştır. Hesaplanan somatotiplere göre betimsel istatistikleri Tablo 1'de verilmiş̧ir. Araştırmaya katılım Helsinki deklarasyonunun (1964) gerektirdiği şekilde katılım prosedürleri için bilgilendirilmiş onam formları ile velilerden izin alınarak, gönüllük esasına dayalı gerçekleştirilmiş̧ir. Araştırmaya katılan tüm katılımcılar, normal motor becerileri olan ve herhangi bir nörolojik ya da motorsal hastalık şüphesi olmayan çocuklar arasından seçilmiştir.

Tablo 1. Grupların Yaş, Boy ve Kilo Ortalamalarına İlişkin Betimsel İstatistikler

\begin{tabular}{llllllll}
\hline & N & Yaş & Sd & Kilo & Sd & Boy & Sd \\
\hline Baskın Endomorfi & $\mathbf{4 2}$ & 11,76 &, 616 & 45,58 & 6,83 & 146,52 & 6,83 \\
Baskın Mezomorfi & $\mathbf{4 7}$ & 11,55 &, 783 & 38,45 & 9,92 & 140,78 & 7,08 \\
Baskın Ektomorfi & $\mathbf{3 4}$ & 11,71 &, 664 & 33,58 & 3,80 & 145,08 & 6,03 \\
Toplam & $\mathbf{1 2 3}$ & 11,66 &, 699 & 39,54 & 9,96 & 143,93 & 7,14 \\
\hline
\end{tabular}




\section{Verilerin Toplanması}

Katılımcıların boy uzunluğu 0,1 cm'e duyarlı metal bir stadiometreyle kiloları ise $01 . \mathrm{kg}^{\prime} \mathrm{ye}$ duyarlı dijital baskül kullanılarak ölçülmüştür. Antropometrik ölçümler, deri kıvrım kalınlığı (DKK), çap, uzunluk ve çevre ölçümleri yapılmıştır. Ölçümlerde $+0,2 \mathrm{~mm}$ hassasiyette Holtain marka set kullanılmıştır. Ölçümler iki kez tekrarlanmıştır, her ölçüm arasında en az 20 saniye ara verilmiştir ve ölçümün ortalaması alınarak kullanılmıştır. DKK, çap ve çevre ölçümleri vücudun sağ tarafından, aynı kişi tarafından iki kez yapılmıştır ve ortalama değerler kullanılmıştır. Somatotip hesaplamaları Healt-Carter formüllerine göre yapılmıştır.

Triseps Deri Kıvrımı: Ayakta kolları yana doğru serbestçe sarkıtılmış durumda üst kolun dikey orta noktasına denk gelen akromion prosesin dış çıkıntısı ile olekranon arasındaki orta noktadan ölçülmüştür.

Suprailiak 1 Deri Kıvrımı: Ayaklar birleşik ve beden dik durumda iken yan gövde orta çizgisinin iliak kreste yakın olan bölgesinden alınmıştır.

Subskapula Deri Kıvrımı: Skapulanın inferior açısının altından $45^{\circ}$ diagonal olarak denek ayakta ve kollarını serbest olarak aşağıya bırakmış durumda iken subskapular deri kıvrım kalınlığı alınmıştır.

Medial Kalf Deri Kıvrımı: Sağ baldırın en geniş bölgesinde kalf çevresinin en geniş olduğu bölgenin medial yüzeyinden dik olarak alınmıştır.

Humerus Epikondil Çap: El pronasyonda, dirsek fleksiyonda iken humerusun lateral ve medial epikondilleri arasındaki uzaklık, santimetre cinsinden ölçülmüştür.

Femur Epikondil Çap: Denek bacakları yere paralel sandalye üzerinde oturur ve diz $90^{\circ}$ bükülü durumda iken femurun en diş ve iç kondillerinin arasındaki uzaklık, santimetre cinsinden ölçülmüştür.

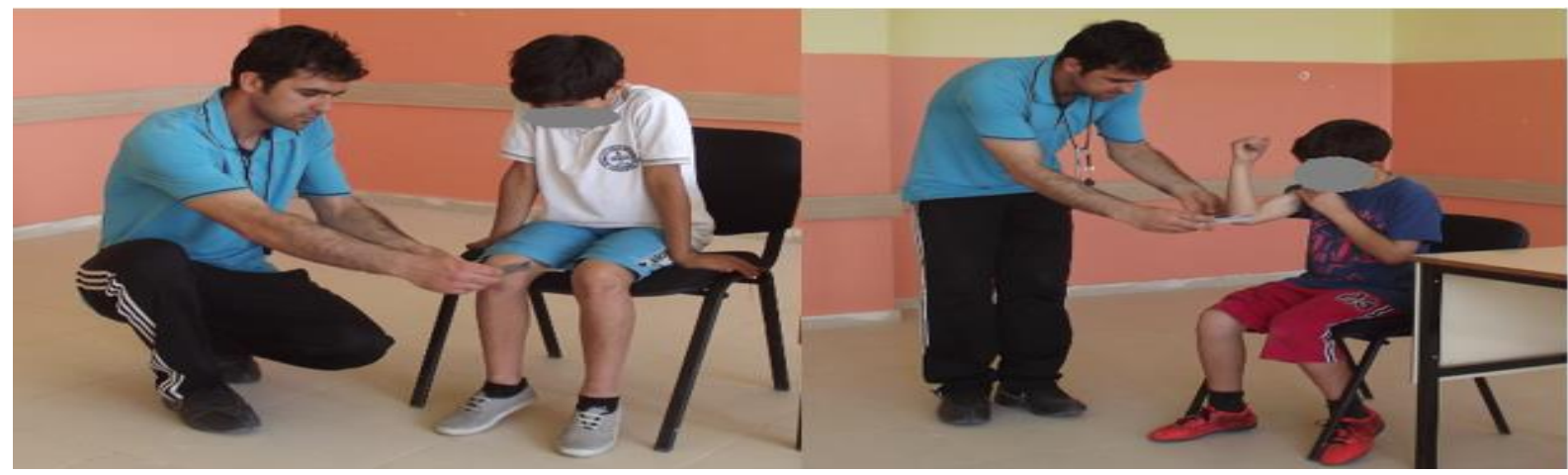

Şekil 1. Femur ve Humerus Ekopindil Çap Ölçümleri 
Biseps Çevresi: Denek ayakta ve kollar aşağıya doğru iken bisepsin çevresi ölçülerek yapılmıştır. Kasılı Biseps Çevresi: Denek ayakta ve biseps kasıldıktan sonra bisepsin çevresi ölçülerek yapılmıştır.

Baldır Çevre: Denek ayakta iken baldırın en kalın noktasının çevresi ölçülmüştür.

\section{Heath-Carter Antropometrik Somatotipi Hesaplanması}

Endomorfi derecesi; triceps, subscapula, suprailiac yağ kalınlıkları toplanarak aşağıdaki formül ile hesapland. $\quad(-0.7182+(0.1451 \mathrm{x})-(0.00068 \times 2)+\quad(0.0000014 \times 3)$ $\mathrm{x}=$ triceps+scapular+suprailiac.

Mezomorfi derecesi; boy, femur ve humerus epicondil çapları ile düzeltilmiş biceps ve baldır çevre ölçülerinin mm cinsinden aynı bölge DKK ölçüleri alınır biceps ve baldır ise yağ kalınlık dereceleri cm'ye çevrilerek çevreden çıkarılarak hesaplandı. (0.858xHumerus epicondil çap $\mathrm{cm})+(0.601 \mathrm{xFemur}$ epicondil çap $\mathrm{cm})+(0.188 \mathrm{x}$ Düzeltilmiş biceps çevre $)+(0,161 \mathrm{x}$ düzeltilmiş calf çevre)-(boyx0.131)+4.5.

Ektomorfi derecesi; boy ve ağırlık oranına bakılarak ponderal indeks (HWR) 40.75 'den büyük ise $=0.732 \mathrm{HWR}-28.58$, Ponderal indeks (HWR) 40,75'e eşit ya da küçük ise $=0,732 \mathrm{HWR}$ 28,58 formülleri kullanılarak hesaplandı. Ponderal indeks (HWR) 38,25'e eşit ya da küçük ise sonuç 0.1 olarak ele alındı (Özer, 2009).

\section{Testlerin Uygulanması}

Testlerden önce, katılımcılar denge ölçüm cihazı hakkında bilgilendirildiler. Her katılımcıya 3-5 dakika cihaza alışmak için deneme yaptırıldı. Testler, katılımcıların en dinlenik olduğu saatlerde (gündüz 09:00-10:00 arası) yapıldı. Gürültü ve sıcaklık gibi çevresel faktörlerin etkilerini önlemek için gerekli önlemler alındıktan sonra testlerin uygulanmasına geçildi.

\section{Tecno Body Öıçüm Cihazı}

Dinamik denge ölçümleri Tecno body PK200WL cihazı kullanılarak yapıldı. Testin uygulanışı katılımcılara açıklandıktan sonra cihazın kalibrasyonu yapıldı. Katılımcılar denge platformununa ayaklar arasındaki mesafe 10 santimetre olacak şekilde ve medial arkın maksimum noktasının izdüşümü x ekseninde olacak şekilde yerleştirildi. Çocuklar için cihazın kolay olan başlığ denge platformuna takılarak 30 saniyelik çift ayak ve 10 saniyelik sağ sol ayak ölçümleri 
yapıldı, test iki defa uygulandı ve iyi olan sonuç kaydedildi. Katılımcı ölçüm sırasında cihazdan düşerse ölçüm tekrarlanmıştır. Test, katılımcının bilgisayar ekranı karşısında bir referans dairesinde sabit kalmaya çalışmasından ibarettir (Akın, 2013).

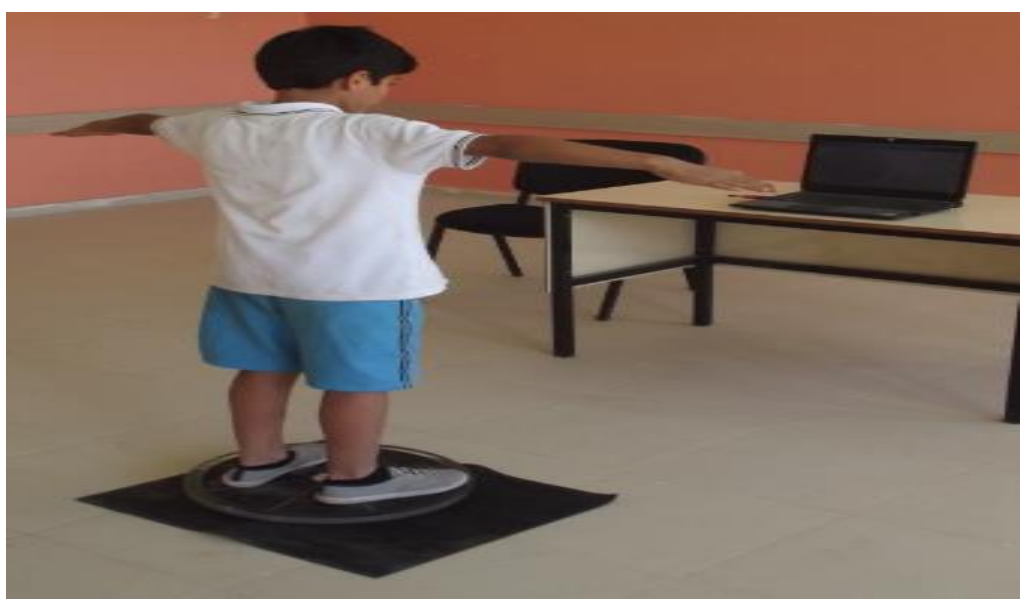

Şekil 2. Tecno Body Dinamik Denge Ölçüm Yöntemi

\section{İstatistiksel Analiz}

Araştırmada betimsel tarama modeli kullanılmıştır. Somatotip özellikleri bulmak için 'Heath-Carter Antropometrik Somatotipi Hesaplanma' tekniği kullanılmıştır. Üç grup arasındaki istatistiksel analiz, parametrik dağılımlarda 'tek yönlü anova', non-parametrik dağılımlarda kruskal wallis testi ile yapılmıştır. İstatistiksel işlemlerde anlamlılık düzeyi 0,05’tir.

\section{BULGULAR}

Çalışmada dinamik denge bulguları Tablo 2'de verilmiştir.

Tablo 2. Tüm Grupların Dinamik Denge Tek Yönlü ANOVA Sonuçları

\begin{tabular}{|c|c|c|c|c|c|c|c|}
\hline Testler & Gruplar & $\mathbf{n}$ & $-\mathbf{x}$ & Ss & $\mathbf{F}$ & $\mathbf{p}$ & Fark \\
\hline \multirow[t]{3}{*}{ PL Çift Ayak } & Baskın Endomorf $(4,21)$ & 42 & 607,23 & 200,26 & \multirow[t]{3}{*}{14,044} & \multirow[t]{3}{*}{,000 } & B-A \\
\hline & Baskın Mezomorf $(4,41)$ & 47 & 446,63 & 74,82 & & & B-C \\
\hline & Baskın Ektomorf $(2,69)$ & 34 & 566,48 & 150,41 & & & \\
\hline \multirow[t]{3}{*}{ PL Sağ Ayak } & Baskın Endomorf $(4,21)$ & 42 & 265,34 & 78,79 & \multirow[t]{3}{*}{7,010} & \multirow[t]{3}{*}{,001 } & B-A \\
\hline & Baskın Mezomorf $(4,41)$ & 47 & 205,11 & 55,80 & & & B-C \\
\hline & Baskın Ektomorf $(2,69)$ & 34 & 270,35 & 132,17 & & & \\
\hline \multirow[t]{3}{*}{ PL Sol Ayak } & Baskın Endomorf $(4,21)$ & 42 & 233,97 & 94,32 & \multirow[t]{3}{*}{5,747} & \multirow[t]{3}{*}{,004 } & B-A \\
\hline & Baskın Mezomorf $(4,41)$ & 47 & 193,86 & 35,95 & & & $\mathrm{~B}-\mathrm{C}$ \\
\hline & Baskın Ektomorf $(2,69)$ & 34 & 255,11 & 111,24 & & & \\
\hline
\end{tabular}

$\mathbf{P L}=$ Perimeter Lenght, A=Endomorf, B=Mezomorf, C=Ektomorf 
Demir, A., ve Akın, M. (2019). 11-12 yaş çocuklarda somatotip özelliklere bağlı dinamik dengelerinin karşılaştırılması. CBÜ Beden Eğitimi ve Spor Bilimleri Dergisi, 14(1), 139-150.

Araştırma bulgularına göre endomorfi ( $n=42) 4,21$, mezomorfi ( $n=47) 4,41$, ektomorfi $(n=34)$ 2,69 olarak bulunmuştur. Tek yönlü anova testiyle yapılan karşılaştırmalar sonucunda baskın mezomorf çocuklar ile baskın endomorf ve baskın ektomorf çocukların PL çift ayak, sağ ayak ve sol ayak dinamik denge değerleri arasında mezomorf lehine anlamlı fark olduğu bulunmuştur $(\mathrm{p}<, 05)$. Baskın endomorf ile baskın ektomorf gruplar arasında ise anlamlı farkın olmadığı $(\mathrm{p}>, 05)$ görülmektedir.

\section{TARTIŞMA VE SONUÇ}

Bu araştırmada, 11-12 yaş sedanter erkek çocukların somatotip özelliklere bağlı dinamik dengelerinin karşılaştırılması amaçlanmıştır. Yapılan karşılaştırmalar sonucunda baskın mezomorf çocuklar ile baskın endomorf ve baskın ektomorf çocukların PL çift ayak, sağ ayak ve sol ayak dinamik denge değerleri arasında anlamlı fark olduğu, baskın endomorf ile baskın ektomorf gruplar arasında ise anlamlı farkın olmadığı bulunmuştur. Genel olarak yağ dokusunun fazlalığı antrenman boyunca performansı negatif etkilemekte ve vücuda fazlaca yük bindirmektedir. Az yağlı bir vücut kütlesi antrenman sırasında yüklenmelere direnç göstererek daha iyi performans sergilemektedir (Mala ve ark., 2015). En başarılı sporcuların kendi branşlarına en uygun fiziksel özelliklere sahip oldukları görülmüştür. Genel hipotez bir sporcunun gerekli fiziksel özelliği olmaksızın yüksek sportif başarıya ulaşamayacağıdır. Sporcuların somatotip incelemesinde somatotipin şampiyonluk performansı için önemli bir seçici faktör olduğu varsayılmıştır (Carter, 1990). Dolayısıyla genel anlamda somatotipin belirlenmesi için yapılan çalışmalar ilgi odağı olmuştur. Örneğin Türkiye' de profesyonel ve milli takım düzeylerindeki sporcular üzerine yapılan çalışmalar bulunmaktadır. Mezomorf özelliğinin baskın olduğu branşlar Judo (İmamoğlu, Kishalı, Çebi ve İmamoğlu, 2000). Kano (Akça ve Müniroğlu, 2006) ve 1. Lig profesyonel futboludur (Ramanlı ve Müniroğlu 2002). Halterciler de endomorf baskın iken (Turnagol ve Demirel, 1992), milli taekwondo takımda ektomorf bileşenleri baskın (Ghorbanzadeh, Akalan, Şahin ve Kirazcı, 2011), olarak bulunmuştur. Yapılan benzer çalışmalarda basketbol yıldız milli takım sporcularının somatotip bileşenleri mezamorfik-ektomorf olarak bulunmuş ve basketbolcuların kaslı uzun boylu oldukları görülmüştür (Erol, Ayan, Mülazımoğlu ve Koçak., 2018). Bunun sebebinin zaten bu özellikteki çocukların basketbola özgü somatotip özelliklerinin avantaj sağladığı ve seçilerek takıma gelmeleri olduğu düşünülmektedir. Futbolcular üzerinde yapılan çalışmalarda somatotip 
Demir, A., ve Akın, M. (2019). 11-12 yaş çocuklarda somatotip özelliklere bağlı dinamik dengelerinin karşılaştırılması. CBÜ Beden Eğitimi ve Spor Bilimleri Dergisi, 14(1), 139-150.

bileşenlerin baskın mezomorf olarak bulunduğu görülmektedir (Ayan, Kaya ve Erol, 2011; Kürkçü ve ark., 2009). 9-12 yaş grubu aerobik jimnastik ve ritmik jimnastik sporcularının fiziksek özelliklerinin araştırıldığı bir araştırmada ise aerobik ve ritmik cimnastikçilerin somatotip değerleri, ektomorfi bileşeninin daha baskın olduğu uzun ince yapıda oldukları bildirilmiştir (Kankal, 2008). Farklı ülkelerde yapılan çalışmalarda da benzer şekilde kassallık özelliğini yansıtan mezomorfi baskın bulunan branşlar vardır. Örneğin, elit genç tenisçilerde (SánchezMuñoz ve ark., 2007) ve genç İtalyan sporcularda (Gualdi-Russo ve Graziani, 1993) baskın mezomorfi ön plandadır. Bu araştırmada okul çağı sedanter erkek çocukların somatotip ortalamaları; mezamorfik endomorf olarak bulunmuştur. Literatürde yapılan çalışmalarla kassallık özelliği benzerlik gösterirken yağl1lık özelliği olarak bilinen endomorfi özelliğinin de fazla çıkmış olması sedanter yaşam tarzına bağlı herhangi bir branşla ilgilenmemeleri ve hareketsiz bir yaşam sürdürmeleri olduğu düşünülmektedir. Ektomorfi özelliğinin az çıkması da olimpik sporcular ya da branşların gereği uzun boylu bireylerin seçilmiş olması ve normal toplumdaki bireylerin, türk standartlarında boy oranına sahip olduklarından kaynaklanabileceği düşünülmektedir. Benzer şekilde sedanter olan 8-10 yaş erkek çocuklarının yetenek seçimi üzerine yapılan araştırmada somatotip bileşenleri mezomorfik-endomorf olarak bulunduğu görülmektedir (Ayan ve Mülazimoğlu, 2009). Dolayısıyla antrenörlerin, sporcuları herhangi bir branşa yönlendirirken bu sonuçlara göre hareket etmeleri ve somatotip özelliklere göre branşlara yönlendirmeleri, sporcuların başarılı olabilmeleri için oldukça önemlidir. Somatotip özellikleri ile denge performanslarını karşılaştıran araştırmada, sporcuların dinamik dengelerinin endomorf, mezomorf ve ektomorf özelliklere göre farklılık gösterdiği fakat statik dengelerinde herhangi bir farklılığın olmadığı bulunmuştur. Endomorf olan sporcuların dinamik dengede daha başarılı olduğu gözlenmiştir (Top ve ark. 2018). Bu araştırmada ise baskın mezomorf olan çocuklar daha başarılı olmuşlardır ve çalışma sporcularla yapılan araştırma ile farklılık göstermektedir. Bunun sebebinin yapılan bu çalışmanın sedanter çocuklar üzerinde olması ve sportif antrenmanların etkisinin olmaması düşünülmektedir. Amacı genç bireylerin dinamik denge skorlarının somatotip özellikler açısından etkilenip etkilenmediğini belirlemek olan farklı bir araştırmada, somatotip farklılıkların dinamik denge üzerinde etkili olmadığı sonucuna varılmıştır (Şenol ve ark. 2018). Bizim araştırmamız, bu araştırmanın sonuçları ile paralellik göstermemektedir. Bazı araştırmalarda da erkek baskın mezomorf çocuklar ile denge arasında pozitif yönde bir ilişki olduğu görülmektedir (Eler, 2018; Erdoğan ve Karatoprak, 2017). 11-13 yaş arasında değişen 90 erkek çocuğun katıldığı 
bir araştırmada da; ektomorf ile denge arasında güçlü bir pozitif ilişki olduğu mezomorf ve endomorf gruplar ile denge arasında ise negatif bir ilişki olduğu bulunmuştur (Salimi ve ark., 2016). $\mathrm{Bu}$ araştırmada ise baskın mezomorf çocukların dengelerinin daha iyi olduğu görülmektedir. Allard ve ark., (2001), çocuklar üzerinde yaptıkları araştırmada, ektomorf grubun postural stabilitesinin daha düşük olduğunu bulmuşlardır. Bunun sebebinin, kas bileşenlerinin az olması ve yüksek ağırlık oranlarına bağlamışlardır. Bu araştırmada da baskın ektomorf grubun baskın endomorf grupla beraber baskın mezomorf gruba göre düşük postural stabilete sergilediği görülmüştür.

Amacı, altı ile dokuz yaşları arasındaki çocuklarda antropometrik özellikler ile denge arasındaki ilişkiyi belirlemek olan ve 158 öğrencinin (88 erkek, 70 kız ) katıldığı bir araştırmada, endomorfik bileşenleri daha baskın olan çocukların hem statik hem de dinamik denge testlerinde daha düşük performans sergiledikleri bulunmuştur (Guzmán-Muñoz ve ark. 2019). Alonso ve ark., (2015), araştırmalarında, duyusal ve antropometrik değişkenler arasındaki ilişkiyi değerlendirmişlerdir. Araştırmalarına yüz birey (50 erkek, 50 kadın;) katılmıştır. Tüm katılımcılar için vücut bileşimi (yağ dokusu, yağsız kitle, kemik mineral içeriği ve kemik mineral yoğunluğu) ve vücut kütlesi, boy, gövde baş uzunluğu, alt ekstremite uzunluğu ve üst ekstremite uzunluğunu ve gözler açık-kapalı statik duruş sırasında denge özelliğini ölçmüşlerdir. Korelasyon analizinde, denge özelliği ve antropometrik değişkenler arasında düşük bir ilişki olduğunu bulmuşlardır. Sonuç olarak, dengenin vücut kompozisyonuna ve boyutuna bağlı olduğunu, boy uzunluğunun denge özelliğini engelleyen antropometrik değişken olduğunu bildirmişlerdir. Samaei ve ark., (2014), da araştırmalarında 141 sağlıklı üniversite öğrencisi üzerinde somatotip özelliğine göre, statik ve dinamik dengenin, düşme riski üzerine etkisini incelemişlerdir. Araştırma sonucunda mezomorf deneklerde daha yüksek derecede statik ve dinamik denge kontrolü bulunurken, endomorf denekler arasında, özellikle hem gözleri açık hem de gözleri kapalıyken, daha düşük derecede bir denge kontrolü bulmuşlardır Ayrıca, yaşları 5-12 arasında değişen, 160 çocuğun katıldığı bir araştırmada, boy, kilo, kol ve ayak uzunluğunun dinamik denge ile olan ilişkisine bakılmıştır. Dinamik denge yeteneği doğrudan kronolojik yaş ile ilgili olduğu, yaşın artmasıyla beraber denge özelliğinin de geliştiği bunun yanı sıra kol uzunluğu ve denge puanları arasında da güçlü ilişki olduğu bulunmuştur (Butz ve ark., 2015). Amacı, sağlıklı kişilerde, instabilite koşulları altında, antropometrik faktörler, vücut kütlesi, vücut kitle indeksi ve denge arasındaki ilişkiyi değerlendirmek olan bir araştırmada, vücut kütlesinin denge özelliğini etkileyen ana antropometrik 
Demir, A., ve Akın, M. (2019). 11-12 yaş çocuklarda somatotip özelliklere bağlı dinamik dengelerinin karşıllaştırılması. CBÜ Beden Eğitimi ve Spor Bilimleri Dergisi, 14(1), 139-150.

faktör olduğu ve tüm değişkenlerle yüksek korelasyon gösterdiği bulunmuştur. Artmış vücut kitle indeksi, dengeyi korumak için daha büyük hareketler gerektirir. Yine aynı çalışmada boy ve beden kitle indeksi, denge ile orta düzeyde korelasyon göstermiştir (Grave ve ark., 2013). Tüm bu araştırmaların sonuçlarına baktığımızda, artan yağ kütlesinin denge özelliğini bozduğu söylenebilir. Bizim araştırmamızda da endomorf olan çocukların daha fazla salınım gösterdikleri ve araştırmamızın yapılan diğer araştırmalarla paralellik gösterdiği görülmektedir.

Sonuç olarak araştırmaya katılan okul çağı çocuklarının somatotip bileşenleri, sedanter çocuklar üzerine yapılan araştırmalarla benzerlik göstermekte fakat sporcu çocuklar üzerine yapılan araştırma sonuçlarıyla farklılık göstermemektedir. Ayrıca somatotip bileşenlerine göre denge performanslarına bakıldığında baskın mezomorf olan grubun baskın ektomorf ve baskın endomorf gruba göre daha iyi denge performansı gösterdiği görülmektedir. Branşa özgü yetenek seçiminde, somatotip özelliklerin dikkate alınması ve antrenman planlamasının belirli vücut tipine uygun olması ile başarı oranının artacağı düşünülmektedir. Bu yüzden antrenörlere, beden eğitimi öğretmenlerine, sporculara somatotip ölçümlerin, yüksek performans ve başarı için önemli bir araç olarak kullanılması önerilebilir. Eğer çocukların somatotip özelliklerine özgü yönlendirme yapılırsa, yanlış branşlaşma ile spora yönelecek çocukların başarısız olma şansı azaltılabilir. Bundan dolayı okul çağı sedanter çocuklarının somatotip değerlerinin ortaya konması ve denge performanslarının karşılaştırılmasının literatüre önemli bir katkı sağlayacağı düşünülmektedir.

\section{KAYNAKLAR}

Akça, F., \& Müniroğlu, S. (2006). Türk erkek kano milli takımı durgunsu kayakçılarının somatotip özelliklerininin incelenmesi. Spormetre Beden Eğitimi ve Spor Bilimleri Dergisi, IV(2),43-47.

Akın, M. (2013). Effect of gymnastics training on dynamic balance abilities in 4-6 years of age children. International Journal of Academic Research, 5(2), 142-146.

Allard, P., Nault, M. L., Hinse, S., LeBlanc, R., \& Labelle, H. (2001). Relationship between morphologic somatotypes and standing posture equilibrium. Annals of human biology, 28(6), 624-633.

Alonso, A. C., Mochizuki, L., Silva Luna, N. M., Ayama, S., Canonica, A. C., \& Greve, J. M. (2015). Relation between the sensory and anthropometric variables in the quiet standing postural control: is the inverted pendulum important for the static balance control?. BioMed research international, (3), 1-5.

Ayan, V., \& Mülazimoğlu, O. (2009). Sporda yetenek seçimi ve spora yönlendirmede 8-10 yaş grubu erkek çocuklarının fiziksel özelliklerinin ve bazı performans profillerinin incelenmesi (Ankara Örneği). Fırat Üniversitesi, Sağllk Biimleri Tip Dergisi, 23(3), 113-118.

Ayan, V., Kaya, M. ve Erol, A. E. (2011). Erkek çocuklarının futbol branşı için somatotip ve performans özelliklerinin incelenmesi. Niğde Üniversitesi Beden Egitimi ve Spor Bilimleri Dergisi, 5(3), 27-31. 
Demir, A., ve Akın, M. (2019). 11-12 yaş çocuklarda somatotip özelliklere bağlı dinamik dengelerinin karşılaştııılması. CBÜ Beden Eğitimi ve Spor Bilimleri Dergisi, 14(1), 139-150.

Beğen, A. (2008). Genç ve elit triatletlerde bisiklet egzersizi sonrasında dengenin değerlendirilmesi. Dokuz Eylül Üniversitesi Sağlık Bilimleri Enstitüsü, Yüksek Lisans, İzmir.

Buśko, K., Pastuszak, A., \& Kalka, E. (2017). Body composition and somatotype of judo athletes and untrained male students as a reference group for comparison in sport. Biomedical Human Kinetics, 9(1), 7-13.

Butz, S. M., Sweeney, J. K., Roberts, P. L., \& Rauh, M. J. (2015). Relationships among age, gender, anthropometric characteristics, and dynamic balance in children 5 to 12 years old. Pediatric physical therapy, 27(2), 126-133.

Carter, J. L., Carter, J. L., \& Heath, B. H. (1990). Somatotyping: development and applications (Vol. 5). Cambridge university press.

Chaudhari, A. M., \& Andriacchi, T. P. (2006). The mechanical consequences of dynamic frontal plane limb alignment for noncontact ACL injury. Journal of biomechanics, 39(2), 330-338.

Davlin, C. D. (2004). Dynamic balance in high level athletes. Perceptual and motor skills, 98(3_suppl), 1171-1176.

Eler, N. (2018). The Relationship Between Body Composition and Physical Fitness Parameters in Children. International Education Studies, 11(9), 71-78.

Erdoğan, E., \& Karatopak, T. (2017). Altyapı Sporcularında Somatotip Özellikler İle Anaerobik Performans ve Dinamik Denge Arasındaki İlişki. Dünya Spor Bilimleri Araştırmaları Kongresi Bildiri Özet Kitabı, Manisa, s517.

Erol, A, E., Ayan, V. Mülazımoğlu, O., ve Koçak M. (2018). Basketbol yıldız milli takım (16 yaş) oyuncularının vücut yağ örüntüsü ve somatotip değerlerinin tespiti. Sport Sciences, 3(2), 108-115.

Eyyüpoğlu, E., Köklü, Y., Özkan, A., ve Akın, M. (2010). Amerikan futbolcularının bazı fiziksel uygunluk özelliklerinin oynadıkları mevkilere göre karşılaştırılması. e-Journal of New World Sciences Academy, 5(2), 127-134.

Geladas, N. D., Nassis, G. P., \& Pavlicevic, S. (2005). Somatic and physical traits affecting sprint swimming performance in young swimmers. International Journal of Sports Medicine, 26(02), 139-144.

Ghorbanzadeh B., Akalan C., Şahin M. ve Kirazcı S. (2011). Türk taekwondo milli takımının somatotip özelliklerinin incelenmesi. eJournal of New World Sciences Academy Sports Sciences,6(3), 169-177.

Gualdi-Russo, E., ve Graziani, I. (1993). Anthropometric somatotype of Italian sport participants. The Journal of sports medicine and physical fitness, 33(3), 282-291.

Guzmán-Muñoz, E. E., Valdés-Badilla, P., Méndez-Rebolledo, G., Concha-Cisternas, Y. F., \& Castillo-Retamal, M. E. (2019). Relación entre el perfil antropométrico y el balance postural estático y dinámico en niños de 6 a 9 años. Nutrición Hospitalaria, 36(1), 32-38.

İmamoğlu, O., Kishalı, N. F., Çebi, M., ve İmamoğlu, H. (2000). Türk judo erkek milli takımında vücut kompozisyonu parametrelerinin incelenmesi. Journal of Physical Education and Sport Sciences, 1(1),1302-2040.

Kabakc1, A. G., \& Yücel, A. H. (2016). Klasik bale eğitimi alacak öğrencilerin somatotip analizi. Cukurova Medical Journal, 41(4), 744-750.

Kankal, M. B. (2008) 9-12 yaş grubu aerobik cimnastik ve ritmik cimnastik sporcularını fiziksel, fizyolojik ve performans özelliklerinin karşılaştırılması. Yüksek Lisans Tezi, Ankara Üniversitesi, Ankara.

Kürkçü, R., Hazar F. ve Özdăg, S. (2009). Futbolcuların vücut kompozisyonu, vücut bileşenleri ve somatotip özellikleri üzerine bir inceleme. Niğde Üniversitesi. Beden Eğitimi ve Spor Bilimleri Dergisi, 3(2), 113-119.

Lidor, R., Falk, B., Arnon, M., \& Cohen, Y. (2005). Measurement of talent in team handball: the questionable use of motor and physical tests. Journal of Strength and Conditioning Research, 19(2), 318.

Mala, L., Maly, T., Zahalka, F., Bunc, V., Kaplan, A., Jebavy, R., \& Tuma, M. (2015). Body composition of elite female players in five different sports games. Journal of human kinetics, 45(1), 207-215. 
Demir, A., ve Akın, M. (2019). 11-12 yaş çocuklarda somatotip özelliklere bağlı dinamik dengelerinin karşılaştırılması. CBÜ Beden Ĕ̈itimi ve Spor Bilimleri Dergisi, 14(1), 139-150.

Marta, C. C., Marinho, D. A., Barbosa, T. M., Carneiro, A. L., Izquierdo, M., \& Marques, M. C. (2013). Effects of body fat and dominant somatotype on explosive strength and aerobic capacity trainability in prepubescent children. The Journal of Strength \& Conditioning Research, 27(12), 3233-3244.

Özer, K. (2009). Kinantropometri Sporda Morfolojik Planlama. Nobel Yayın Dağıtım, Ankara.

Ramanlı, F. Müniroğlu, S. (2002). Farklı liglerde mücadele eden profesyonel futbol takımları sporcularının somatotip özellikleri üzerine bir inceleme. Spor Bilimleri Dergisi, 13(4), 32-40.

Salimi, H. R., Heidari, N., \& Salimi, A. (2016). The relation between somatotype with aerobic capacity and balance in the boys 11-13 years. Turkish Journal of Kinesiology, 2(2), 23-25.

Samaei, A., Bakhtiary, A. H., \& Hajihasani, A. (2014). Endomorphs show higher postural sway than other somatotypes subjects. Middle East Journal of Rehabilitation and Health, 1(2), 23-47.

Sánchez-Muñoz, C., Sanz, D., ve Zabala, M. (2007). Anthropometric characteristics, body composition and somatotype of elite junior tennis players. British journal of Sports Medicine, 41(11), 793-799.

Sánchez-Muñoz, C., Zabala, M., \& Williams, K. (2012). Anthropometric variables and its usage to characterise elite youth athletes. In Handbook of anthropometry (pp. 1865-1888). Springer, New York.

Sayuri Tookuni, K., Bolliger Neto, R., Martins Pereira, C. A., Rúbio de Souza, D., Greve, J. M. D. A., \& Ayala, A. D. A. (2005). Análise comparativa do controle postural de indivíduos com e sem lesão do ligamento cruzado anterior do joelho. Acta Ortopédica Brasileira, 13(3), 115-119.

Söğüt, M., Müniroğlu, R. S., \& Deliceoğlu, G. (2004). Farklı Kategorilerdeki Genç Erkek Tenis Oyuncularının Antropometrik ve Somatot,p Özelliklerinin İncelenmesi. Spormetre Beden Ĕ̆itimi ve Spor Bilimleri Dergisi, 2(4), 155-162.

Şenol, D., Özbağ, D., Kafkas, M. E., Açak, M., Baysal, Ö., Kafkas, A. Ş., ... \& Özen, G. (2018). The clinical effects of somatotype difference on isokinetic knee muscle strength and dynamic balance scores. Turkish Journal of Physical Medicine \& Rehabilitation (2587-0823), 64(1), 28-36.

Top, E., Çelenk, Ç., Marangoz, I., Aktug, Z. B., Yilmaz, T., \& Akil, M. (2018). The Effect of Somatotype Characteristics of Athletes on the Balance Performance. Journal of Education and Learning, 7(5), 174-180.

Turnagol, H. H., Demirel, H. (1992). Türk milli haltercilerin somatotip profilleri ve bazı antropometrik özelliklerinin performansla ilişkisi. Spor Bilimleri Dergisi, 3(3), 11-18. 